\title{
Compreensão e entendimento de saúde vivenciado por pessoas em situação de rua
}

RESUMO | Objetivo: analisar o conhecimento sobre o direito à saúde de pessoas em situação de rua. Método: estudo de natureza descritivo-exploratório com abordagem qualitativa, desenvolvido com 17 pessoas em situação de rua em um centro de referência especializado do Distrito Federal, Brasil. Os dados foram coletados a partir de entrevistas gravadas, transcritas e analisadas mediante a análise de conteúdo. A pesquisa foi aprovada pelo Comitê de Ética em Pesquisa sob o parecer $n^{\circ}$ 3.604.566. Resultados: o conhecimento acerca dos direitos à saúde mostra-se insuficiente; o acesso aos serviços de saúde foi dificultado pela exigência de endereço fixo; e o preconceito pela condição de morador de rua e/ou pela orientação sexual esteve presente. Conclusão: evidencia-se a necessidade de educação em saúde e a reformulação das práticas dos profissionais de saúde para a garantia do acesso aos serviços de saúde para a população em situação de rua.

Palavras-chaves: Pessoas em Situação de Rua; Política Pública; Vulnerabilidade em Saúde; Enfermagem.

ABSTRACT | Objective: to analyze the knowledge about the right to health of people living on the streets. Method: a descriptiveexploratory study with a qualitative approach, developed with 17 homeless people in a specialized reference center in the Federal District, Brazil. Data were collected from recorded interviews, transcribed and analyzed through content analysis. The research was approved by the Research Ethics Committee under opinion $n^{\circ} 3.604 .566$. Results: knowledge about health rights is insufficient; access to health services was hampered by the requirement for a fixed address; and prejudice due to the condition of homelessness and / or sexual orientation was present. Conclusion: the need for health education and the reformulation of health professionals' practices is evident in order to guarantee access to health services for the homeless population.

Keywords: Homeless Persons; Public Policy; Health Vulnerability; Nursing.

RESUMEN | Objetivo: analizar el conocimiento sobre el derecho a la salud de las personas que viven en la calle. Método: estudio descriptivo-exploratorio con enfoque cualitativo, desarrollado con 17 personas sin hogar en un centro de referencia especializado en el Distrito Federal, Brasil. Los datos fueron recolectados de entrevistas grabadas, transcritas y analizadas mediante análisis de contenido. La investigación fue aprobada por el Comité de Ética en Investigación bajo la opinión n 3.604.566. Resultados: el conocimiento sobre los derechos de salud es insuficiente; el acceso a los servicios de salud se vio obstaculizado por el requisito de una dirección fija; y el prejuicio debido a la condición de personas sin hogar y / u orientación sexual estuvo presente. Conclusión: es evidente la necesidad de educación sanitaria y la reformulación de las prácticas de los profesionales de la salud para garantizar el acceso a los servicios de salud para la población sin hogar.

Descriptores: Personas sin Hogar; Política Pública; Vulnerabilidad en Salud; Enfermería.

\section{Paulo Roberto Chaves Júnior}

Enfermeiro. Universidade Paulista (UNIP), Campus Brasília, Distrito Federal, Brasil.

\section{Ricardo Saraiva Aguiar}

Professor Assistente. Curso de Graduação em Enfermagem, Universidade Paulista (UNIP), Campus Brasília, Distrito Federal, Brasil.

Recebido em: 29/01/2020

Aprovado em: 01/03/2020

INTRODUÇÃO

$\Lambda$ população em situação de rua constitui um público crescente nas cidades e acaba refletindo processos sociais desiguais e excludentes dos direitos básicos como saúde, trabalho, educação, moradia, entretenimento e segurança. ${ }^{1-2}$

Sua existência é um fenômeno social que vem assumindo novas expressões nas sociedades contemporâneas, particularmente nos centros urbanos. Esse grupo marginalizado pela sociedade tem como habitação os logradouros ou albergues públicos ou filantrópicos e, ainda, vivencia situações de trabalho, condições de vida e inserções sociais precárias. ${ }^{3}$

Diante disso, o setor saúde acaba sendo um componente importante, particularmente, relacionado ao acesso dessa população aos serviços. Dessa forma, em 2009 o Ministério da Saúde publicou a Política Nacio- nal para a População em Situação de Rua (PNPSR) com a finalidade de garantir a igualdade e equidade; o respeito e dignidade ao ser humano; o direito a vivência comunitária e familiar; o reconhecimento e respeito à vida e à cidadania; o atendimento humanizado e universalizado; o respeito às diferenças sociais e de origem, raça, idade, nacionalidade, gênero, orientação sexual e religiosa, com atenção especial à portadores de deficiência. ${ }^{3}$

Ademais, em 2013 foi publicada a Política Nacional de Saúde LGBT com objetivo de garantir uma promoção integral a saúde de gays, lésbicas, bissexuais, travestis e transexuais com a premissa de eliminar preconceitos e discriminação institucional, contribuindo para a diminuição da desigualdade e reafirmando o SUS como um sistema universal, integral e equitativo. Destaca-se ainda a publicação do Decreto n ${ }^{\circ} 8.727$, de 28 de abril de 2016, que reconhece o nome social e a iden- 
Chaves Júnior, P.R:; Aguiar, R.S.; Compreensão e entendimento de saúde vivenciado por pessoas em situaçăo de rua

tidade de gênero de transexuais e travestis. ${ }^{4}$

Com a declaração de Alma Ata em 1978, a atenção primária à saúde (APS) ganhou impulso e tornou-se porta de entrada dos sistemas de saúde, reforçando esse nível de atenção como uma ferramenta importante para a garantia do acesso. ${ }^{5}$ Mas, apesar do movimento progressivo de acesso à saúde da população em situação de rua, ainda são encontradas diversas barreiras que impedem ou retardam a busca pelo atendimento de saúde devido ao preconceito, inabilidade e/ ou desrespeito demostrado pelo profissional ao se deparar com um paciente que pode não estar em um bom estado de higiene e/ ou sob efeito de alguma substância. ${ }^{6-7}$

Dessa forma, o cuidado destinado a essa população ainda é desproporcional a sua necessidade, não apenas pela sua política ainda recente, mas também pela carência de literatura científica, deixando uma lacuna no conhecimento acerca da temática. ${ }^{8}$ Sob essa perspectiva, destaca-se a questão que norteou a presente proposta investigativa: qual o conhecimento sobre o direito à saúde e como é o acesso aos serviços de saúde das pessoas em situação de rua?

Portanto, este estudo tem o objetivo de analisar o conhecimento sobre o direito à saúde de pessoas em situação de rua.

\section{MÉTODO}

Trata-se de um estudo de natureza descritivo-exploratório com abordagem qualitativa, desenvolvido em um centro de referência especializado para população em situação de rua do Distrito Federal, Brasil.

Participaram deste estudo pessoas em situação de rua que atenderam os seguintes critérios de inclusão: homens e mulheres acima de 18 anos de idade em situação de rua; que são atendidos pelo centro de referência especializado para população em situação de rua do Distrito Federal, Brasil; e que não estejam sob efeito de substâncias lícitas ou ilícitas. Foram excluídos crianças e adolescentes em situação de rua; pessoas que estavam sob efeito de substâncias lícitas ou ilícitas; e pessoas em situação de rua que não eram atendidas pelo centro de re- ferência especializado para população em situação de rua do Distrito Federal, Brasil.

A determinação do número de participantes obedeceu ao critério de saturação das informações e ao final da coleta de dados contou-se com a participação de dezessete pessoas em situação de rua.

A coleta de dados ocorreu no mês de outubro de 2019, em dois momentos. No primeiro, foi observado a movimentação de fluxo e a relação interpessoal de usuários e funcionários do centro de referência especializado para população em situação de rua do Distrito Federal, Brasil. No segundo momento, aplicou-se um roteiro de entrevista semiestruturado a cada participante, dividido em duas partes: a primeira, com os dados de identificação dos entrevistados (sexo biológico, gênero, idade, estado civil, filhos, grau de instrução e tempo em situação de rua) e a segunda, com as perguntas norteadoras baseadas no objetivo da pesquisa.

O tempo médio das entrevistas foi de 30 minutos, sendo realizadas principalmente no período da manhã devido ao maior fluxo de pessoas. As perguntas norteadoras foram: 1) Você sabe quais são os seus direitos em relação à saúde? Pode nos falar mais sobre eles. 2) Já foi negado a você algum tipo de atendimento em uma unidade de saúde por sua condição de rua? Caso sim, como foi? 3) Você já vivenciou algum preconceito em uma unidade de saúde por ser morador de rua? Caso sim, como foi esse(s) episódio(s)?

Objetivando a privacidade, as entrevistas ocorreram de forma individual e foram realizadas em espaço privativo da instituição. Os discursos foram obtidos por um gravador de áudio e com a concessão das pessoas em situação de rua por meio da assinatura e/ou colocação da impressão digital no Termo de Consentimento Livre e Esclarecido (TCLE).

As falas foram transcritas e analisadas por meio da proposta de análise de conteúdo, a qual se organiza nas seguintes fases: pré-análise, exploração do material, tratamento dos resultados, inferência e interpretação. ${ }^{9}$

Na pré-análise, houve a leitura flutuante, seguida da constituição do corpus de acordo com o objetivo proposto. Para a exploração do material, realizou-se a co- dificação por meio das palavras ou frases semelhantes nos discursos. Na fase de tratamento dos resultados e da interpretação, foi possível agrupar os fragmentos das narrativas com o intuito de visualizar as informações obtidas com plenitude, bem como abranger as inferências previstas.

Atendendo a garantia do sigilo das identidades dos participantes para a apresentação dos relatos foi utilizado a codificação alfanumérica (ex: PSR1, PSR2, PSR3), onde PSR corresponde à pessoa em situação de rua e os numerais à ordem de sua entrevista.

Os aspectos éticos foram respeitados, conforme exigência da Resolução $\mathrm{n}^{\circ}$ 466/2012, do Conselho Nacional de Saúde, que trata da pesquisa em seres humanos. O projeto foi submetido e aprovado pelo Comitê de Ética em Pesquisa (CEP) da Universidade Paulista (UNIP) sob o parecer $\mathrm{n}^{\circ}$ 3.604.566 (CAAE 19702619.2.0000.5512), de 27 de setembro de 2019.

\section{RESULTADOS}

Foram entrevistadas 17 pessoas em situação de rua, sendo 41,2\% do sexo biológico feminino e $58,8 \%$ do sexo biológico masculino. Ressalta-se que 3 entrevistados (17,6\%) do sexo biológico masculino se identificaram como transgênero. A média de idade variou de 19 a 52 anos. Em relação ao grau de instrução, 5,9\% são analfabetos; 41,2\% tinham o ensino fundamental incompleto; $11,8 \%$ o ensino fundamental completo; $29,3 \%$ tinham o ensino médio incompleto; e 11,8\% o ensino médio completo. A média de tempo de vivência na rua, variou de 2 meses a 7 anos.

Diante disso, foi identificado que a população em situação de rua tinha pouca compreensão acerca de seus direitos relacionados à saúde, como percebe-se a partir dos depoimentos:

Eu também nunca fui atrás, mas agora estou precisando de algumas consultas. Eu sei que tenho direito como qualquer pessoa, mas não sei quais [risos]. Acho que falta a informação né. (PSR2)

Não sei e acho que é por falta de informação. Aqui tem mais 
informações sobre o uso de substâncias. (PSR7)

Tá faltando muita informação. Já vi muitas pessoas em situação de rua não buscando atendimento por não saber aonde ir. (PSR9)

Nunca tive informação quanto a isso. Eu estou buscando agora principalmente na área de psicologia porque eu percebo que tenho alguns transtornos e preciso acompanhar. Fui ao CAPS, mas achei muito estranho e não me senti muito bem. No lugar tinha muita gente alterada. (PSR14)

Sim, todos os direitos. Só não sei quais são eles. Acho que isso é por falta de informação. (PSR15)

Normalmente, o processo saúde-doença dessa população não está ligada somente a doenças suscetíveis a eles, mas também a agravos que se manifestam através da violência, de atropelamentos, da dependência química, entre outros. ${ }^{4}$ Contudo, foi identificado algumas indagações relacionadas a busca pelo entendimento e apropriação de seus direitos, conforme percebe-se pelos depoimentos:

Nem sempre somos atendidos, então nem sempre temos direito. Mas, eu me cuido e tomo meus remédios. (PSR1)

Eu tenho direito ao pré-natal, medicamento, atendimento [...], mas é muito difícil ser atendido. Tenho algumas informações agora que estou grávida. Eles falam que o uso de drogas pode deixar meu bebê mal. (PSR11)

Tenho direito de atendimento em qualquer local da rede pública. Se o hospital público não tiver o atendimento adequado para mim eles podem me mandar para o hospital particular que o Estado paga e o Estado não pode me privar do atendimento. (PSR12)

Mais ou menos. Eu estou fazendo um curso de redução de danos e lá fala isso também - sobre nossos direitos a saúde. Acho que só não sabe dos seus direitos quem não corre atrás deles. (PSR13)

Quando questionado se já foi negado o atendimento em uma unidade de saúde devido a condição de rua, boa parte dos entrevistados revelaram dificuldades de acesso, conforme identifica-se nos depoimentos a seguir: Já sim. Eles não quiseram me atender. Falaram que eu estava na rua e não tinha um endereço fixo e que sem ele não seria atendida. Eu realmente estava precisando do atendimento. (PSR1)

Uma vez busquei atendimento no hospital [...] e ao chegar lá o moço do balcão pediu o endereço e eu falei que morava na rua e não tinha endereço. Então ele falou: aí fica difícil! Você vai sentar aí e aguardar atendimento. (PSR5)

Tem quatro meses que estou com um machucado no pé e fui na [...] tentar ser atendida e aí mostrei tudo isso e a mulher falou que sem endereço não teria atendimento. Depois fui em um posto de saúde no Gama e lá a doutora me tratou "super" bem e me passou exames e medicamento. (PSR8)

Eu estou grávida e na Bahia uma funcionária falou que nós não seríamos atendidos por não termos moradia e nem endereço. Acho que porque no dia eu e meu esposo estávamos sujos. (PSR11)

Contudo, os entrevistados que afirmaram nunca terem sido negado algum atendimento em uma unidade de saúde trouxeram questões importantes para um debate, conforme percebe-se:

A gente sente que tem uma diferença no atendimento, mas nunca me negaram das vezes que eu precisei. Também não vou muito a hospitais e "postinhos". Tenho a saúde boa. (PSR2)

Não, mas quase não preciso. Eu sempre me consultei aqui no
Consultório na Rua e nunca precisei ir a outro lugar. (PSR6)

Não porque eu sempre vou direto ao Consultório na Rua e lá eles atendem a gente muito bem. (PSR13)

Não, eu sempre fui atendida aqui no centro [...] e não sou muito de ir em hospital. (PSR16)

Algo válido a ser compreendido é a não adesão ao tratamento e/ou a não procura pelo serviço devido à experiência negativa vivenciada por esses indivíduos em uma unidade de saúde. Quando indagado sobre o preconceito vivido em uma unidade de saúde, muitos dos entrevistados relataram já terem vivenciado um ou mais episódios de preconceito:

No [...] fui falar com uma moça que eu estou meio desequilibrado e não estou conseguindo dormir direito e ela falou que eu estava querendo era abrigo e não tratamento. (PSR3)

Eles falam: Ah, isso é morador de rua, é andarilho e por isso está assim. Quando falamos que estamos em situação de rua eles demoram no atendimento para ver se nós desistimos do atendimento. (PSR7)

Quando falei que morava na rua a mulher levou um susto e falou que sem endereço não teria atendimento. (PSR8)

Eles ficam julgando a gente por estar na rua. Eles ficam fazendo piadinha entre eles na nossa frente. (PSR10)

Aqui em Brasília uma doutora no hospital de [...] me furou cinco vezes para procurar a veia e eu falei que estava doendo e ela falou: você não sente a dor da rua e a dor da droga, vai sentir dor de uma agulhinha? Eu mandei ela ir para o [palavrão] e enfiar a agulhinha [palavrão]. (PSR11)

Na clínica da família. Eu tinha bebido um pouco e a enfermeira ficou falando: nossa que cheiro de cachaça, nossa 'tá' fedendo. (PSR17)

Ainda sobre o preconceito, foi identificado na fala de duas mulheres transgêne- 
Chaves Júnior, P.R; Aguiar, R.S.; Compreensão e entendimento de saúde vivenciado por pessoas em situaçăo de rua

ros o preconceito não só pela situação de rua, mas também pela orientação sexual ficando visível na fala a desmotivação pela procura ao serviço de saúde:

Muito preconceito. Eu tenho várias situações, mas prefiro não comentar. Não é só por ser moradora de rua, mas por ser transgênero também. Fazem comentários, ficam cochichando e acaba que não dá nem vontade de voltar lá. Eles também chamam pelo nome da certidão mesmo sabendo meu nome social só para provocar. (PSR15)

Já fui chamada de "viadinho" pelo segurança e alguns funcionários que ficavam rindo, mas eu não ligo para isso. (PSR 16)

\section{DISCUSSÃo}

A população em situação de rua encontra, por diversas vezes, o esquecimento das estruturas convencionais da atual sociedade, deixando de usufruir da convivência familiar, social e por muitas vezes da cidadania da vida humana. Contudo, a Constituição Federal deixa claro que a saúde é um direito de todos e um dever do estado, validando assim a universalidade no Sistema Único de Saúde (SUS). ${ }^{3}$

A partir da falta de conhecimento identificada no estudo, acrescenta-se que não adianta ter somente o direito nas políticas de saúde, mas sim o entendimento do que ele proporciona com o intuito de abarcar a participação de todos no processo saúde-doença-cuidado, pois a deficiência no conhecimento e a ausência de suporte adequado juntamente com o preconceito sofrido faz com que esses indivíduos abandone o tratamento e deixe de procurar os serviços de saúde de modo rotineiro. ${ }^{10}$

Diante disso, a percepção do processo saúde-doença-cuidado torna-se um dispositivo extremamente necessário para avaliação e planejamento com a finalidade de deliberar ações com caráter de prevenção e recuperação da saúde da população em situação de rua. Assim, a educação em saúde se faz necessária para o empoderamento e para a apropriação dos direitos de cada indivíduo. ${ }^{11}$

Nesse contexto, o processo de redução de danos vem ajudando a ampliar o conhecimento e tornando o sujeito um ator ativo em seu tratamento e estado de saúde. O processo inclui a distribuição de insumos, o contato com o indivíduo no local onde vive, ações de educação e prevenção em saúde e o contato com todos os envolvidos no território. O trabalhador é levado a olhar o usuário como um todo e com todas as suas individualidades, visando o melhor a ser feito sem definir metas. A redução de danos como diretriz assistencial e metodologia ajuda o profissional a traçar estratégias por meio de diversas direções, tendo como objetivo a participação integral do indivíduo, possibilitando a construção de um processo onde o usuário se torna responsável pelas decisões tomadas em seu tratamento. ${ }^{12}$

Observou-se ainda que a exigência de endereço fixo para a garantia do atendimento foi uma das principais barreiras encontradas a partir dos depoimentos. Tal solicitação justifica-se muitas vezes devido ao entendimento de que a APS se organiza de modo a definir seu território adscrito pelo domicílio fixo, mas esta situação expõe a população em situação de rua a falta de acesso aos serviços de saúde devido a inflexibilidade nessa questão. ${ }^{13}$

A necessidade de endereço fixo acaba dificultando ainda mais o acesso à saúde dessa população, mas por outro lado essa forma de organização é responsável pela logística dos serviços de saúde, bem como o apoio a referência e contra referência nos níveis de saúde, porém tal ferramenta necessita de adaptações a fim de ser equânime devido a complexidade desta população específica. ${ }^{14}$

Vale ressaltar que nenhuma pessoa, independente de raça, cor, etnia, gênero ou classe pode deixar de ser atendida pelo SUS por falta de residência, documento e/ ou cartão nacional de saúde (CNS) conforme descrito na Portaria GM/MS n 940 , de 28 de abril de 2011, que diz não ser necessário a comprovação de endereço de pessoas em situação de rua para a realização de atendimentos de saúde. ${ }^{15}$

Outra situação relacionada a dificuldade de acesso aos serviços de saúde por esta população está associada ao despreparo e/ou o preconceito no atendimento realizado por profissionais que compõem a rede de atenção à saúde. Atitude que acaba causando o afastamento do usuário e o rompimento de vínculo estabelecido anteriormente. ${ }^{16}$ Normalmente, o preconceito está relacionado a falta de higiene ou devido ao consumo/abuso de substâncias lícitas ou ilícitas. ${ }^{13}$

Ademais, os trechos mostram a realidade de muitos que entendem a necessidade de procura dos serviços de saúde somente quando há a presença de alguma enfermidade, desconhecendo assim ações de promoção da saúde. Nota-se nas falas a importância da equipe de Consultório na Rua para essa população, tendo ele como um serviço especializado e referenciado a eles. ${ }^{5}$

Assim, o Consultório na Rua é visto como a principal porta de entrada da população em situação de rua ao serviço de saúde com a oferta de atenção que visa o cuidado integrado, tornando-se fundamental para o processo de saúde-doença-cuidado, buscando e incentivando a participação ativa do usuário, promovendo maior abrangência da atenção e visando compreender a pluralidade de cada indivíduo; tal prática incentiva a promoção da saúde de modo dinâmico, objetivando a resolução das demandas. ${ }^{12}$

Dessa forma, o Consultório na Rua torna-se uma estratégia desafiadora no trabalho em saúde, cabendo também aos profissionais atuantes na equipe a importante função de exercer todas as diretrizes e ações da PNPSR dedicada a fim de tornar o serviço de saúde equânime para as pessoas em situação de rua. ${ }^{15}$

Constatou-se ainda através das falas a falta de preparo, inabilidade e o preconceito demostrado pela atitude de alguns profissionais, deixando de lado a realização de uma escuta qualificada e de um acolhimento adequado. Deste modo, confirma-se o comprometimento nos princípios da universalidade ao acesso, da equidade em ações e serviços e da integralidade da assistência. ${ }^{3}$

Ainda há muita inadequação organizacional no que se refere ao tratamento por parte do profissional na rede de atenção à saúde, encontrando preconceitos e estigmas relacionados a esses indivíduos. Desta forma, 
faz-se necessário o engajamento dos gestores a fim de consagrar a política de cuidado que compreenda essa população como pessoas de direitos. ${ }^{10}$ Ademais, existe a necessidade de capacitação dos profissionais a fim de viabilizar uma melhora no trabalho com intuito de reforçar a rede de comunicação Intersetorial, estabelecendo parcerias, discutindo casos, realizando atendimento compartilhado de modo a propiciar um trabalho em equipe de modo transversal. ${ }^{12}$

A fim de evitar preconceitos relacionados à população LGBTQI+, em 2013 foi publicada a Política Nacional de Saúde LGBT com objetivo de garantir uma promoção integral a saúde de gays, lésbicas, bissexuais, travestis e transexuais com a premissa de eliminar preconceitos e discriminação institucional, contribuindo para a diminuição da desigualdade e reafirmando o SUS como um sistema universal, integral e equitativo. Destaca-se ainda a publicação do Decreto $\mathrm{n}^{\circ}$ 8.727, de 28 de abril de 2016, que reconhece o nome social e a identidade de gênero de transexuais e travestis. ${ }^{4}$
Desse modo, são ações necessárias para o enfrentamento de discriminações relacionadas a orientação sexual, raça, cor e gênero a realização de seminários; preparação de profissionais para atender pessoas LGBTQI+; educação populacional e educação permanente, objetivado o respeito e o reconhecimento de pessoas transexuais e travestis, com ênfase na garantia do direito a saúde dessa população. ${ }^{4}$

De modo geral, as falas neste estudo estão em concordância no que diz respeito à deficiência de conhecimento acerca dos direitos à saúde, a dificuldade no acesso aos serviços de saúde, tendo como questões pertinentes a burocracia pelo próprio serviço, a obrigatoriedade de endereço fixo e o preconceito pela condição de pessoa em situação de rua e/ou pela orientação sexual.

Portanto, a população em situação de rua apresenta uma realidade distante da desejada, demonstra muitas vezes precarização social e no acesso à saúde. Assim, o conhecimento é a palavra-chave no que se refere à superação desse ciclo vicioso de desrespeito e de preconceito, pois prestar atendimento adequado é tarefa de todo profissional da saúde, sendo um compromisso ético com todos os indivíduos. ${ }^{17}$

\section{CONCLUSÃO}

Evidencia-se a necessidade de educação em saúde da população em situação de rua e a reformulação das práticas de saúde de modo a evitar e/ou reduzir danos, garantindo assim a utilização dos recursos disponíveis em sua plenitude por esta população.

Desse modo, a capacitação dos profissionais de saúde é um ponto essencial a fim de gerar um maior esclarecimento sobre a pluralidade encontrada na realidade vivenciada por esses indivíduos, fazendo do profissional um instrumento capaz de modificar a realidade de saúde dessa população.

Assim, as limitações do estudo acreditam-se que esteja relacionada a sua realização em uma única local, uma vez que a ampliação para outras unidades poderia propiciar uma análise ampliada.

\section{Referências}

1. Vale AR, Vecchia MD. "UPA é nós aqui mesmo": as redes de apoio social no cuidado à saúde da população em situação de rua em um município de pequeno porte. Saúde Soc São Paulo. 2019;28(1):222-234. Disponível em: http://www.scielo.br/pdf/sausoc/v28n1/1984-0470-sausoc-28-01-222.pdf

2. Paiva IKS, Lira CDG, Justino JMR, Miranda MGO, Saraiva AKM. Direito à saúde da população em situação de rua: reflexões sobre a problemática. Ciênc Saúde Colet. 2016;21(8):2595-2606. Disponível em: http://www.scielo.br/pdf/csc/v21n8/ 1413-8123-csc-21-08-2595.pdf

3. Hino $P$, Santos JO, Rosa AS. Pessoas que vivenciam situação de rua sob o olhar da saúde. Rev bras enferm. 2018;71(supl1):732-40. Disponível em: http://www. scielo.br/pdf/reben/v71s1/pt_0034-7167-reben-71-s1-0684.pdf

4. Popadiuk GS, Oliveira DC, Signorelli MC. A Política Nacional de Saúde Integral de Lésbicas, Gays, Bissexuais e Transgêneros (LGBT) e 0 acesso ao processo transexualizador no Sistema Único de Saúde (SUS): avanços e desafios. Ciênc saúde coletiva. 2017; 22(5):1509-1520. Disponível em: http://www.scielo.br/scielo. php?script=sci_arttext\&pid=S1413-81232017002501509\&lng=en

5. Vargas ER, Macerata I. Contribuições das equipes de Consultório na Rua para o cuidado e a gestão da atenção básica. Rev panam salud pública. 2018;42:e170. Disponivel em: https://scielosp.org/pdf/rpsp/2018.v42/e170/pt

6. Londero MFP, Ceccim RB, Bilibio LFS. Consultório de/na rua: desafio para um cuidado em verso na saúde. Interface (Botucatu, Online). 2014;18(49):251260. Disponível em: http://www.scielo.br/pdf/icse/v18n49/1807-5762-icse-1807-576220130738.pdf

7. Hallais JAS, Barros NF. Consultório na rua: visibilidades, invisibilidades e hipervisibilidade. Cad Saúde Pública (Online). 2015;31(7):1497-1504. Disponível em: http://www.scielo.br/pdf/csp/v31n7/0102-311X-csp-31-7-1497.pdf

8. Santos CF, Ceccim RB. Encontros na rua: possibilidades de saúde em um consultório a céu aberto. Interface (Botucatu, Online). 2018;22(67):1043-1052. Disponível em: http://www.scielo.br/pdf/icse/v22n67/1807-5762-icse-22-67-1043.pdf 9. Minayo MCS. 0 desafio do conhecimento. 14 ed. São Paulo: Hucitec; 2014.
10. Sicari AA, Zanella AV. Pessoas em situação de sua no Brasil: revisão sistemática. Psicol ciênc prof. 2018;38(4):662-679. Disponível em: http://www.scielo.br/pdf/ pcp/v38n4/1982-3703-pcp-38-04-0662.pdf

11. Mota FO, Fonseca RMAM, Santos JE, Gallassi AD. Aspectos do cuidado integral para pessoas em situação de rua acompanhadas por serviço de saúde e de assistência social: um olhar para e pela terapia ocupacional. Cad Bras Ter Ocup. 2019;27(4):806-816. Disponivel em: http://www.scielo.br/pdf/cadbto/v27n4/ 2526-8910-cadbto-2526-8910ctoA01809.pdf

12. Simões TRBA, Couto MCV, Miranda L, Delgado PGG. Missão e efetividade dos Consultórios na Rua: uma experiência de produção de consenso. Saúde debate. 2017;41(114):963-975. Disponível em: http://www.scielo.br/scielo.php?script=sci_arttext\&pid=S0103-11042017000300963\&lng=en

13. Wijk LBV, Mângia EF. Atenção psicossocial e o cuidado em saúde à população em situação de rua: uma revisão integrativa. Ciênc Saúde Colet. 2019;24(9):3357-3368. Disponível em: http://www.scielo.br/pdf/csc/v24n9/14138123-csc-24-09-3357.pdf

14. Lira CDG, Justino JMR, Paiva IKS, Miranda MGO, Saraiva AKM. 0 acesso da população em situação de rua é um direito negado? REME rev min enferm. 2018. Disponível em: https://www.reme.org.br/artigo/detalhes/1298

15. Abreu D. Consultório na rua e redução de danos: estratégias de ampliação da vida. Rev bras med fam comunidade. 2017;12(39):1-2. Disponivel em: https:// www.rbmfc.org.br/rbmfc/article/download/1435/832

16. Cardoso AC, Santos DS, Mishima SM, Anjos DSC, Jorge JS, Santana HP. Challenges and potentialities of nursing work in street medical offices. Rev. latinoam enferm. 2018;26:e3045. Disponivel em: http://www.scielo.br/scielo.php?script=sci_abstract\&pid=S0104-11692018000100358\&lng=en\&nrm=iso

17. Abreu D, Oliveira WF. Atenção à saúde da população em situação de rua: um desafio para o Consultório na Rua e para o Sistema Único de Saúde. Cad Saúde Pública (Online). 2017;33(2):e00196916. Disponível em: http://www.scielo.br/pdf/ csp/v33n2/1678-4464-csp-33-02-e00196916.pdf 